\title{
A comparison of the tribological behaviour of Y-TZP in tea and coffee under micro-abrasion conditions
}

\author{
S. Sharifi ${ }^{1}$ and M.M. Stack ${ }^{1}$ \\ ${ }^{1}$ Department of Mechanical and Aerospace Engineering \\ University of Strathclyde
}

75 Montrose St.

G1 1XJ

Glasgow

\begin{abstract}
The micro-abrasion of YTZP, a candidate dental restorative material, was investigated in a range of caffeine containing solutions which included tea and coffee. Additions of sugar and milk were used to test the effects of viscosity and $\mathrm{pH}$ on the wear rate. The results indicated a significant increase in wear rate in the various solutions, with some correlation between wear rate and increases in viscosity and this was linked to enhance particle entrainment in the more viscous solutions. The generally lower wear rate in tea compared to coffee was associated with a longer aging period in this solution before uniform wear was observed. Micro-abrasion maps were used to characterise the differences in performance for the material in the environments studied.
\end{abstract}




\section{Introduction}

Many people appreciate the strong bitter taste of coffee through the negative reinforcing effects of caffeine; the repeated consumption of a drink containing caffeine or glucose increases the preference for the drink [1]. However, it has been reported that the general consumption of soft drinks, excluding milk and water, damages teeth, because they typically contain sugar and have a low pH value. The acidity of these drinks erodes enamel. Also, plaque micro-organisms metabolise the sugars in the drinks to generate organic acids that cause demineralisation, leading to dental caries. The detrimental effects of consuming soft drinks on dental hard tissues, either acidogenic or cariogenic, are unavoidable as the neutralisation capabilities of saliva flow and salivary components continually decreases over time [2].

Dental defects may require the restoration or replacement of damaged tissues. A dental restorative material should have the capability to recreate the lost function or restore aesthetic appearance [3]. Due to the required biocompatibility, chemical stability, aesthetics, and processing technologies, ceramics, more specifically zirconia-based ceramics, have been widely used in dental practice for the last two decades. Zirconia ceramics were mainly used as the core material inside dental crowns, in the form of bi-layer restorations followed by the fusion of porcelain veneer shells onto them. Today, as a result of development in manufacturing technologies (CAD/CAM) and by increasing the translucency of zirconia ceramics, full contour zirconia crowns which exhibit excellent mechanical properties without any required subsequent processes (e.g. veneering) can be used. Due to their smaller range of strength variations, full-zirconia restorations have become more popular since they have solved porcelain chipping problems, which were commonly encountered in bi-layer structures $[4,5]$.

Recently, despite the desirable properties of zirconia ceramics, the phenomenon of zirconia ageing has caused some concerns regarding the long-term implementation of this material. Ageing takes place in tetragonal zirconia polycrystalline (TZP) ceramics by a slow tetragonal-to-monoclinic phase transformation on the surface in contact with water or body fluid, which may lead to surface roughening, grain pull out, and micro-cracking. Initial ageing improves the mechanical properties of zirconia, due to the creation a compressive surface layer of monoclinic phase on the ceramic, such as bending strength and fracture toughness. However, further ageing leads to deterioration of the material. In the Lawson review [6], it was reported that there are compositions and conditions under which ageing will not occur. There are a few steps which minimise the ageing susceptibility of these materials, including adding (or increasing the amount of) stabilisers such as yttria or ceria, the addition of a small amount of silica, and processing temperature. The use of yttria clearly increases the ageing resistance while preserving toughness and strength. It also retains the high temperature tetragonal structure of zirconia ceramics. Extra care should be taken during the sintering process to ensure it is conducted within the right temperature range $\left(1400-1450^{\circ} \mathrm{C}\right)$. Higher temperatures cause a dual cubical micro-structure, which, enriched by yttrium, leads to a lack of yttrium content in the neighbouring tetragonal grains, and subsequently increases the ageing susceptibility. Moreover, the sintering process at lower temperatures does not produce fully dense materials $[7,8]$.

As a result, yttria tetragonal zirconia poly-crystalline (Y-TZP), containing 3 mol\% yttria $\left(\mathrm{Y}_{2} \mathrm{O}_{3}\right)$ as a stabiliser, usually referred as biomedical grade zirconia, has become very attractive as a wear-resistant material in dental practice. This is due to the high density, good sinterability, improved fracture toughness, and particularly its superplasticity, which is very useful in ceramic forming and joining. However, because of the diversity of tests and the lack of absolute data of the wear behaviour and mechanisms of $\mathrm{Y}$-TZP, the potential applications of this material are still limited [9-11]. The tribological behaviour of dental restorations is mainly affected by the mechanical properties and superficial microstructure of the material. It has been reported that abrasive wear is the main tribological behaviour in the oral cavity [4]. The abrasive wear rate can also be influenced by the properties of the environment. In previous work, the effects of tea, a very common soft drink, on the micro abrasive behaviour of Y-TZP as a dental restorative material, were studied [12]. The aim of this work, after examining the effects of coffee on the abrasive behaviour of Y-TZP, is to compare the wear mechanisms and generate a body of data as a reference for the wear behaviour Y-TZP in popular caffeine containing soft drinks. 


\section{Materials and Methods}

In this study, the micro-abrasive behaviour of Y-TZP in caffeine based solutions is investigated in accordance with BS EN 1071-6: 2007: "Advanced technical ceramics, Methods of test for ceramic coatings: Determination of the abrasion resistance of coatings by a micro-abrasion wear test", by running ball-cratering abrasive wear tests.

\subsection{Test samples}

3\% yttria doped zirconia discs, provided by National Cheng Kung University, Taiwan, were used to conduct the experiments. The sample surfaces were polished with fine diamond paste $(6-0.3 \mu \mathrm{m})$ and then ultrasonically cleaned in de-ionised water to remove any remaining debris. The circular samples were machined, circumferentially at a very low temperature, into regular octagons ( $36 \mathrm{~mm}$ across) for improved access on the rig platform. The thickness of the samples was $3.4 \mathrm{~mm}$. Table 1 exhibits the mechanical properties of the samples.

\subsection{Slurries}

The Y-TZP samples were tested with seven different solutions: boiled water (for reference), plain tea and coffee, tea and coffee with additional sugar, and tea and coffee with additional milk. PG Tips ${ }^{\circledR}$ (London, UK) Pyramid tea bags were used to make the tea, prepared using the 'tea brewed with freshly boiled water for 2 minutes' instructions. As there is no significant difference between the viscosity of spray dried coffee and freeze dried coffee [13], the coffee was made using Nescafé Original ${ }^{\circledR}$ (York, UK) (spray dried) which is a blend of Arabica and Robusta beans. The manufacturer's recommended concentration, $12 \mathrm{gl}^{-1}$, was used to prepare the coffee [14]. The solutions with added sugar were prepared with 2 teaspoons of sugar per serving, $28.57 \mathrm{gl}^{-1}$ in total. The solutions with added milk were prepared such that $10 \%$ of the final solution was milk. Test slurries were prepared by combining the drink solutions with calcined alumina particles $(9 \mu \mathrm{m})$ (Logitech, UK), an abrasive powder commonly used in simulating oral cavity conditions, at a concentration of $30 \mathrm{gl}^{-}$ 1 , to simulate food bolus during mastication [15]. The hardness of calcined alumina (9 in Moh's scale) makes it an excellent abrasive particle for examining Y-TZP under severe conditions. The flatness of the alumina particles effectively spreads the load at the contact interface [16]. The mechanical properties of the particles are listed in table 1.

The composition of tea and coffee are both based on bioactive phytochemicals, such as amino acids, phenolic acids and polyphenols, with more acidity in coffee [17]. Table 2 presents the properties of the slurries. The addition of alumina particles slightly elevates the $\mathrm{pH}$ value of the drink solutions due to the chemical reaction $\left(\mathrm{Al}_{2} \mathrm{O}_{3}+3 \mathrm{H}_{2} \mathrm{O} \rightarrow 2 \mathrm{Al}(\mathrm{OH})_{3}\right)$ in the slurry. The viscosity of the slurries was measured using a $\mathrm{CLS}^{2} 500$ Carri-Med rheometer. The viscosity of the slurries did not change significantly with increasing shear rate; therefore, the mean values have been reported. The temperature range of the drinks during consumption is estimated between 45 to $50^{\circ} \mathrm{C}$. To keep the temperature of the slurries in this range during the tests, slurry containers were kept in a reservoir with heightened temperature at all times. A small propeller, operating at $1330 \mathrm{rpm}$ near the bottom of the container, was used during the tests maintain the suspension of the abrasive particles in the slurry. Each of the test slurries were used for a maximum of 3 hours to maintain a consistent viscosity [13].

\begin{tabular}{c|ccc}
\hline Material Property & Y-TZP & UHMWPE & Alumina \\
\hline Density(kg/m ${ }^{3}$ ) & 6000 & $931-935$ & 3800 \\
Young's Modulus (GPa) & $195-210$ & 0.689 & 351 \\
Hardness (Vickers) & $1330-1470$ & 541 & 2035 \\
Fracture Toughness (MPa/m) & $7-10$ & $3.5-6$ & 3.5 \\
\hline
\end{tabular}




\begin{tabular}{|c|c|c|c|c|}
\hline Slurry & $p H$ & $\begin{array}{l}\text { Viscosity at } \\
45^{\circ} \mathrm{C}(\mathrm{CP})\end{array}$ & $\begin{array}{c}\text { Temperature at sample in } \\
\text { operation }\left({ }^{\circ} \mathrm{C}\right)\end{array}$ & $\begin{array}{c}\text { Density at } 45^{\circ} \mathrm{C} \\
\left(\mathrm{kg} / \mathrm{m}^{3}\right)\end{array}$ \\
\hline Coffee & 4.6 & 0.781 & $48 \pm 2$ & 1040.2 \\
\hline Coffee + sugar & 4.6 & 0.835 & $48 \pm 2$ & 1069 \\
\hline Coffee + milk & 5.6 & 0.764 & $48 \pm 2$ & 1043.5 \\
\hline Tea & 5.3 & 0.726 & $47 \pm 2$ & 1032 \\
\hline Tea + sugar & 5.3 & 0.728 & $48 \pm 2$ & 1060 \\
\hline Tea + milk & 6.0 & 0.721 & $47 \pm 2$ & 1033 \\
\hline Water & 7 & 0.696 & $48 \pm 2$ & 1012 \\
\hline
\end{tabular}

Table 2 - The properties of the slurries

\subsection{Test rig}

The tests were conducted using a TE-66 Micro-Scale Abrasion Tester (Plint TE-66, Phoenix Tribology, Reading, UK). The mechanism of the test rig is explained elsewhere [12]. Figure 1 shows a schematic view of the rig.

Ultra-high-molecular-weight polyethylene (UHMWPE) balls, of $25.4 \mathrm{~mm}$ diameter, (K-mac Plastics, Michigan, USA) were used as the cratering spheres (See table 1). UHMWPE has a smooth molecular profile with long chain molecules sheared across each other. This gives UHMWPE excellent sliding properties such as the development of films, at the contact interface, made of molecular chains oriented parallel to the sliding direction. Therefore, this material is capable of having the friction coefficient of 0.1 against hard counterfaces [18]. Additionally, the slurry likely further decreases this value.

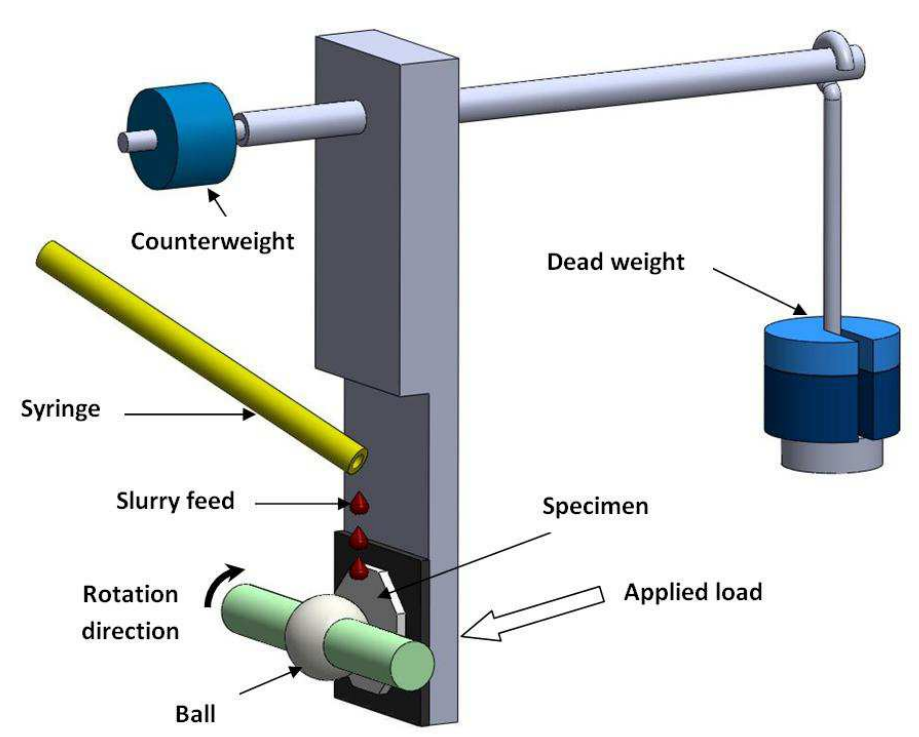

Figure 1 - The schematic view of the test rig

The high chemical resistance of UHMWPE may result in low inter-phase bonding; however, the mechanical activation process solves this problem and also increases the wear resistance of UHMWPE to a superior level [19]. A new cratering ball was used for each type of slurry to control for differences in the slurry composition, and the ball was rotated between tests to minimise the possible influence of ball deformation.

\subsection{Methodology}

Each test applied a normal load of 3, 4, and $5 \mathrm{~N}$ to the sample, for 1, 2, and 3 hours. The load, duration, properties of the slurry mixture, sliding distance, and sliding velocity are the main factors that influence wear rate [20, 21]. The rotational speed of the ball was $150 \mathrm{rpm}(0.2 \mathrm{~m} / \mathrm{s}$ linear velocity). Previous research shows that the heat generated at the interface is negligible due to the high temperature of the slurry [12]. Studies show that the sliding distance per chewing cycle is 0.5 $-1 \mathrm{~mm}$ with a rate of $60-80$ cycles/min, which occurs $10-30 \mathrm{mins} /$ day [4, 22-24]. This means the average sliding distance per tooth is approximately $1 \mathrm{~m}$ /day. Because a 1 hour test is equivalent to $718.17 \mathrm{~m}$ in sliding distance, each test hour simulates 2 years of tooth wear; therefore, these experiments simulate the equivalent of 6 years of wear on a Y-TZP implant. Table 3 shows the test conditions. 
Test conditions

\begin{tabular}{l|c}
\hline Applied normal loads & 3,4 , and $5 \mathrm{~N}$ \\
Sliding velocity & $150 \mathrm{rev} / \mathrm{min}(0.2 \mathrm{~m} / \mathrm{s})$ \\
Tests duration & 1,2, and $3 \mathrm{hrs}$ \\
Sliding distance & $718.17 \mathrm{~m} / \mathrm{hr}$ \\
\hline
\end{tabular}

\section{Results}

\subsection{Volume loss}

Y-TZP absorbs water when placed in an aqueous environment, as is the case for the slurry environment in the experimental rig or in the presence of body fluids in the oral cavity. This absorption increases the mass of the Y-TZP while the mechanical wear decreases the mass through material loss. Without accurate measures of both mass increase and decrease, the mass loss measurement method is not as accurate as a volume loss method. Wear scars were inspected using scanning electron microscopy (S-3700 N Tungsten Filament SEM, Hitachi High-Technologies, Europe). Because the geometry of the wear scars is relatively spherical, the volume loss of each scar has been calculated using equation 1 :

$V=\frac{\pi b^{4}}{64 R} \quad$ for $\quad b<<R$

where $b$ is the diameter of the scar and $R$ is the radius of the spherical counter-body (cratering ball) [25]. In the majority of cases, the edges of the spherical scars were quite clear; however, 2 out of 63 cases showed spherical scarring with 'scuffed' annular regions instead of clear edges. This phenomenon occurs particularly when the samples are softer than the spherical counter-body. However, from table 1 it is obvious that Y-TZP is much harder than UHMWPE; therefore, this may be evidence of ageing. Previous work has shown that annulus ridges are quasi-stable and tend to break down, eventually, to reveal a normal spherical wear scar; therefore, cases without clear edges may still be accurately evaluated [25].

The wear scars were also measured using a stylus profilometer (SJ-500, Mitutoyo, UK). The
Figure 2-Volume loss measurements

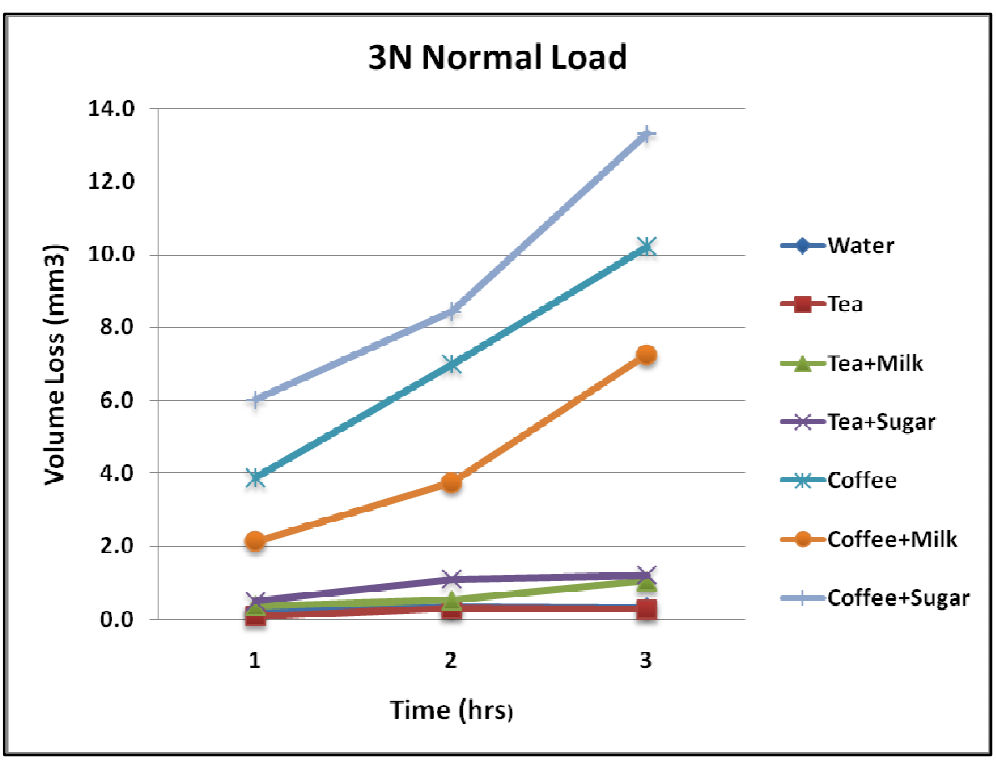

Fig 2 (a) - Volume loss under $3 \mathrm{~N}$ normal load

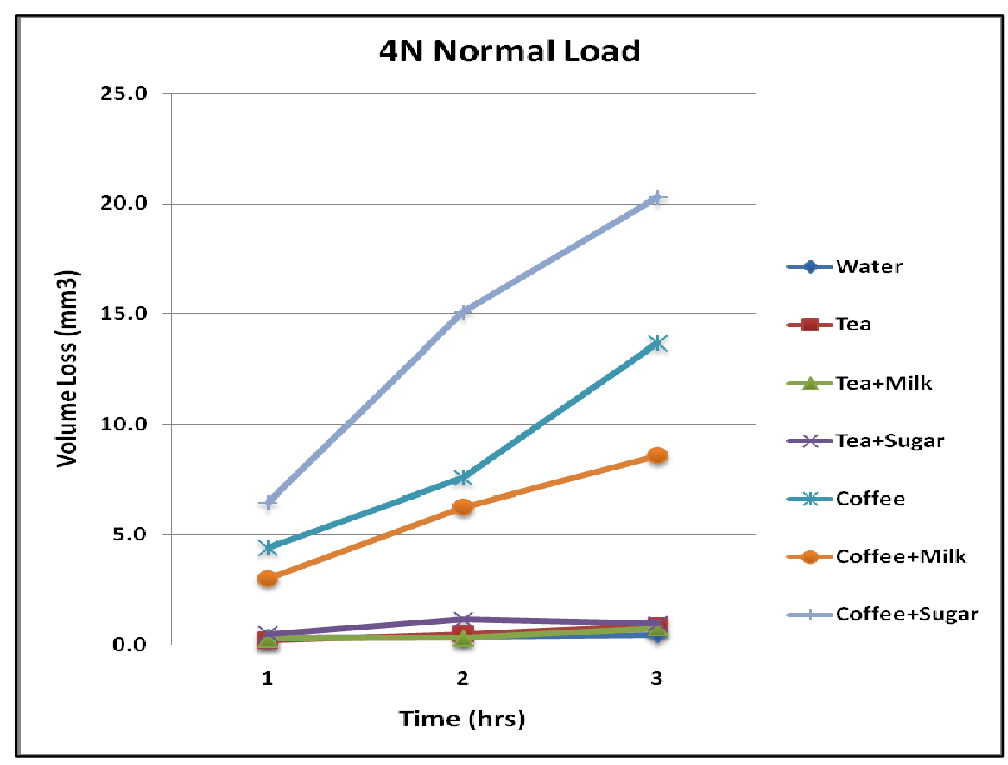

Fig 2 (b) - Volume loss under 4N normal load 
profilometry results validated the volume loss from SEM measurements with a deviation of only $3.9 \%$.

It was determined that the wear scar curvatures imitate the curvature of the spherical counter-body. Figure 2 presents the volume loss measurements. It is clear that coffee slurries cause a higher volume loss than tea slurries.

The volume loss associated with coffee solutions consistently increases with greater applied loads and longer duration (or increased sliding distance); whereas the volume loss associated with tea solutions do not follow a consistent trend under the same conditions. This variation implies that volume loss is affected by additional factors, which are discussed below.

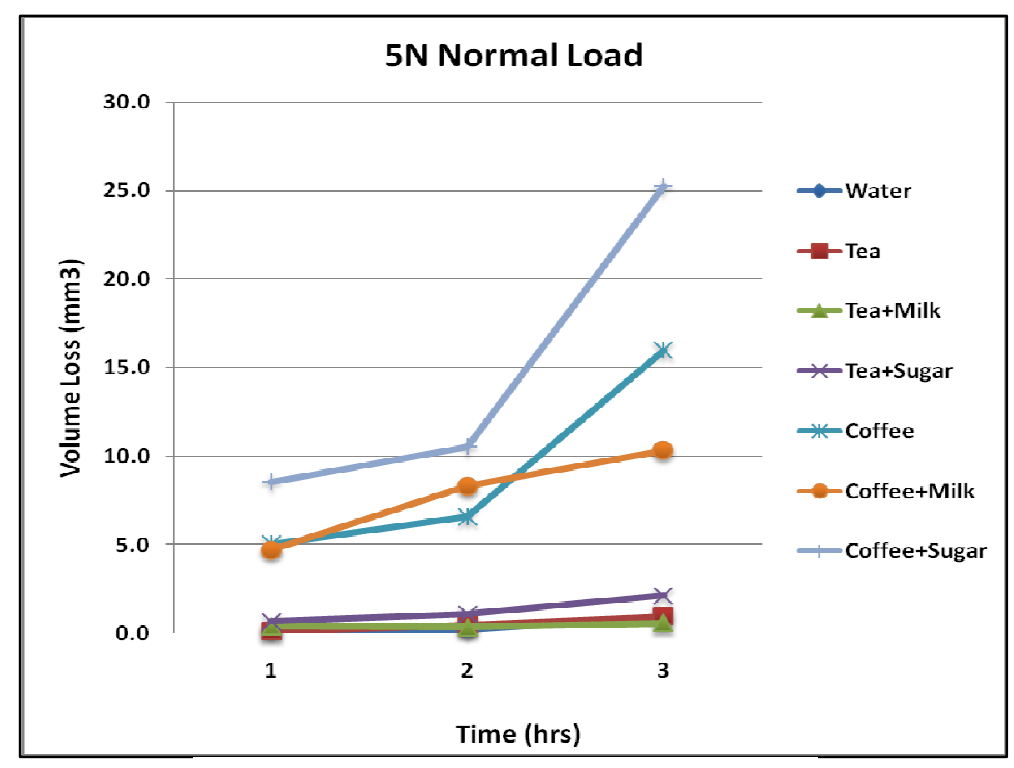

Fig 2 (c) - Volume loss under $5 \mathrm{~N}$ normal load

\subsection{SEM analysis}

The dominant wear regime in the wear scars was 3-2-body mechanism with predomination of 2-body grooving, regardless of the type of slurry [26]. Figure 3 exhibits an example the similarity of the wear scars created by tea and coffee slurries. Figure $3(\mathrm{a})$ is a close-up of the wear scars after a 3 hour test in tea+milk slurry under $4 \mathrm{~N}$ normal load, and figure $3(\mathrm{~b})$ is the wear scars after a 3 hour test in coffee+sugar slurry under $5 \mathrm{~N}$ normal load.
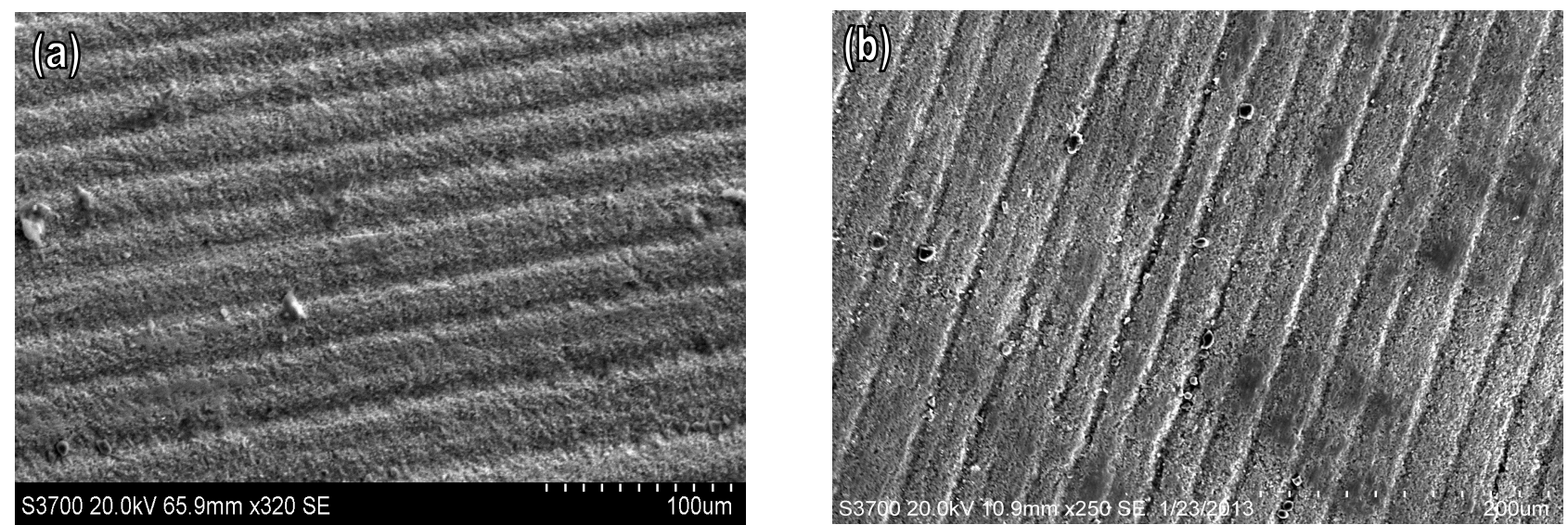

Figure 3 - Wear scars after 3 hrs tests (a) in tea+milk under $4 \mathrm{~N}$ load, (b) in coffee+sugar under $5 \mathrm{~N}$ load

SEM and XRD inspection of the spherical counterbody showed that alumina particles had clearly embedded in the cratering ball surface. Following exposure, the mass loss of the counterface balls was increased up to $1.26 \%$ and their final volume had increased by up to $2.39 \%$ due to the embedded alumina particles. This explains the domination of the 2-body grooving wear regime. This also indicates that the counterface ball and the samples are not in direct contact during the experiments, it is technically the alumina particles that create the wear scars on the surface of the specimen [25].

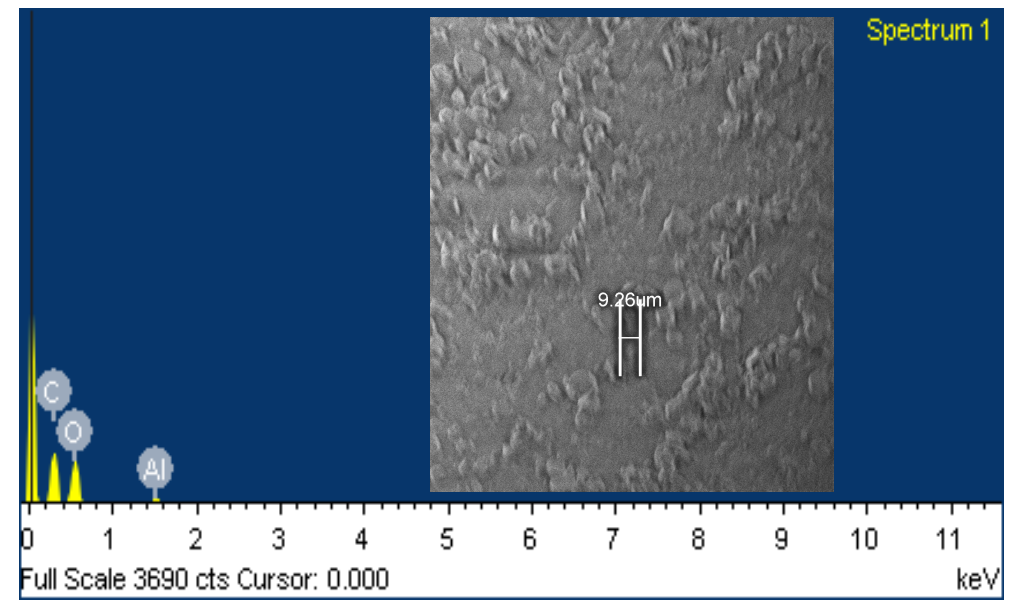

Figure $4-\mathrm{XRD}$ results and SEM analysis after a $2 \mathrm{hrs}$ test 
Figure 4 shows an example of the XRD and SEM investigation of one the counterface balls after a 2 hrs test. It was observed through microscopy that, despite the deeper craters and higher volume loss, craters created in coffee slurries were more uniform than craters created in tea slurries, which showed grain pull-outs and micro cracks. These findings are discussed below. Figure 5 shows an example of these phenomena.
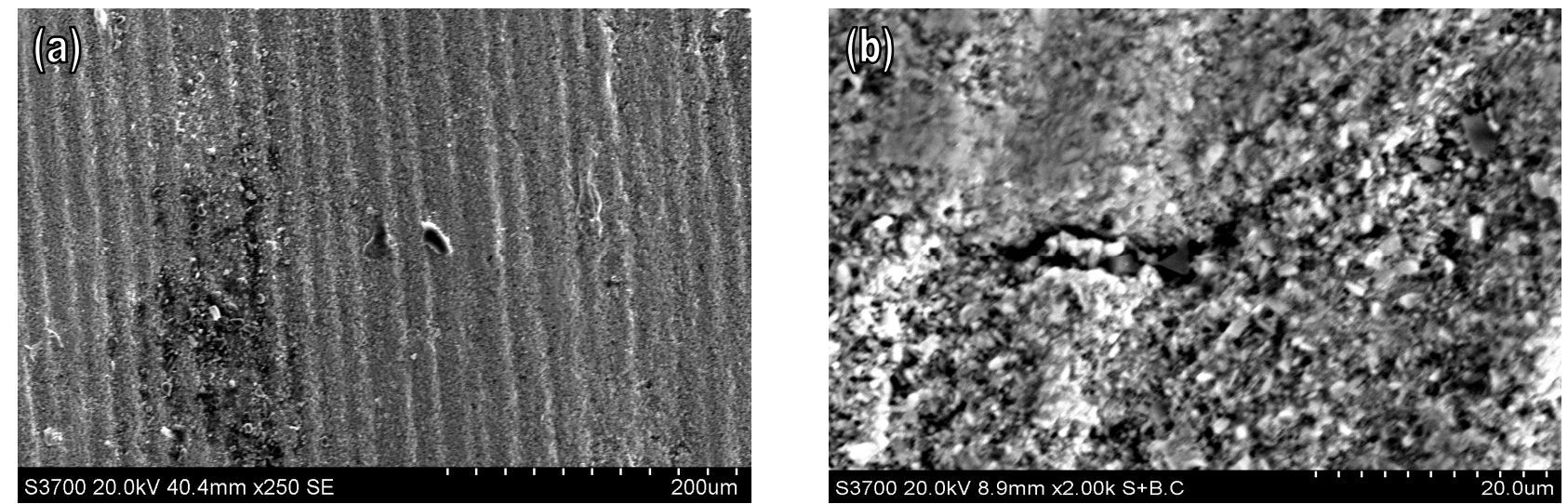

Figure 5 - (a) a grain pull-out incident, (b) a micro crack

\subsection{Wear maps}

Different approaches may be used to combine the available data in order to interpret the wear mechanisms that have taken place. In order to more accurately study and predict the behaviour of Y-TZP, this study presents the data as wear maps. Figure 6 illustrates the behaviour of Y-TZP based on volume loss in three coffee solutions under different loads and exposure times (sliding distance). With a maximum volume loss of $25.247 \mathrm{~mm}^{3}$, volume loss has been classified into 4 categories:

Very low: $\quad V \leq 0.15^{*} V_{\max }$

Low:

$$
0.15 * V_{\max }<V \leq 0.30 * V_{\max }
$$

Medium: $\quad 0.30 * V_{\max }<V \leq 0.60 * V_{\max }$

High: $\quad 0.60 * V_{\max }<V$.

where $V$ is the volume loss and $V_{\text {max }}$ is the maximum volume loss.

The data from all the wear in tea slurries falls under the 'very low' category, so tea slurry wear maps are not shown here; however, the wear mechanisms of $\mathrm{Y}$-TZP in tea slurries have been specifically discussed in previous work [12].

Figure 6 shows that, although the adjustable parameters (normal load and exposure time) are equal for the tests conducted in different slurries, the wear rates can be extremely different. For
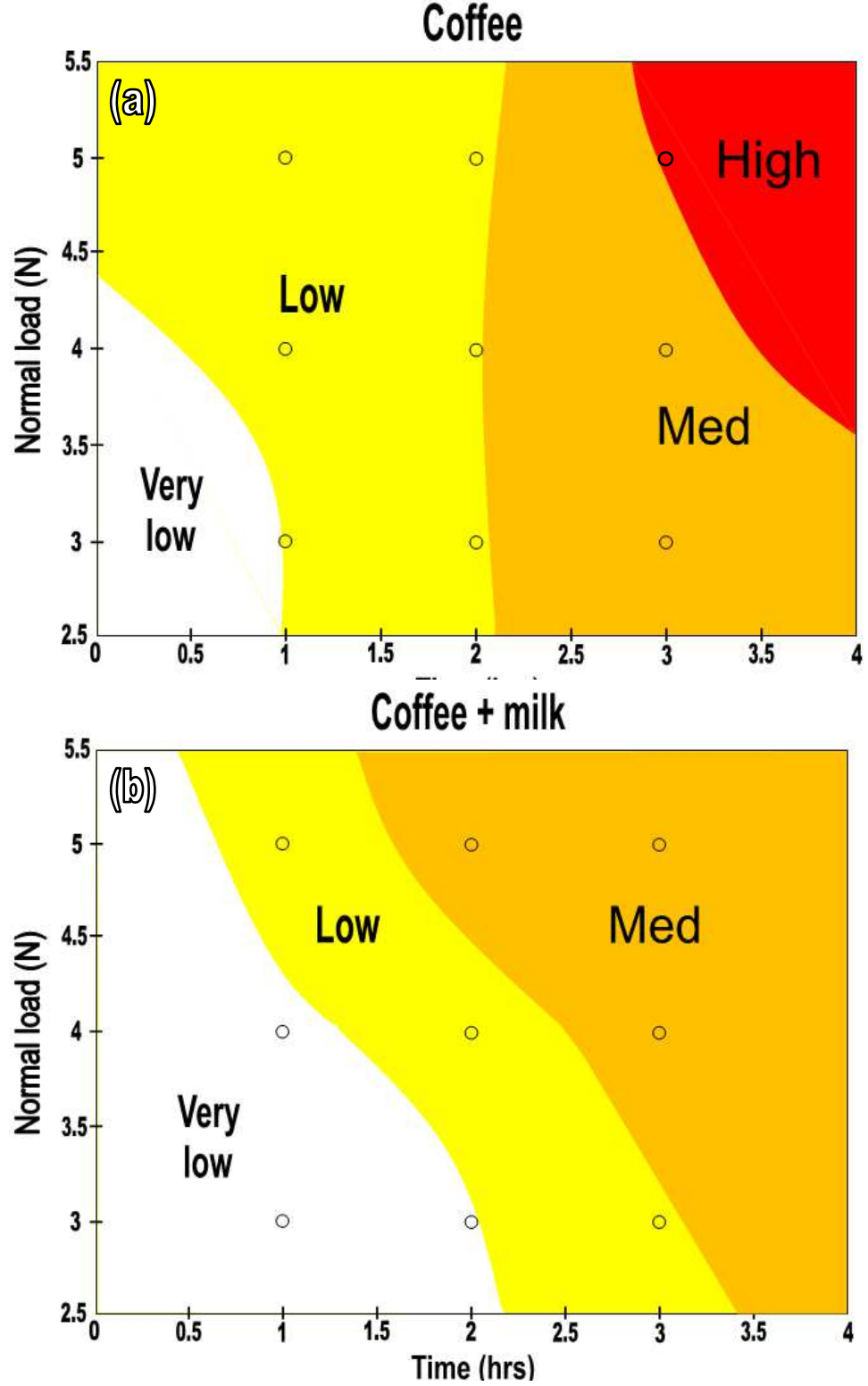

Figure 6(b) - Wear map of Y-TZP in Coffee+milk slurry (load/time) 


\section{Coffee + sugar}

example, in figure $6(\mathrm{~b})$, the wear map shows that the wear rate of a coffee+milk slurry is much lower than that of a coffee+sugar slurry (figure 6(c)). The data in table 2 shows that the coffee+sugar slurry possesses a higher viscosity and lower $\mathrm{pH}$ than the coffee+milk slurry. This indicates that $\mathrm{pH}$ and viscosity, along with applied load and exposure time, can influence wear rate. Therefore, the lower viscosity and the higher $\mathrm{pH}$ of tea slurries, compared to that of coffee slurries, can explain why the wear rates of tea slurries fall into the 'very low' category.

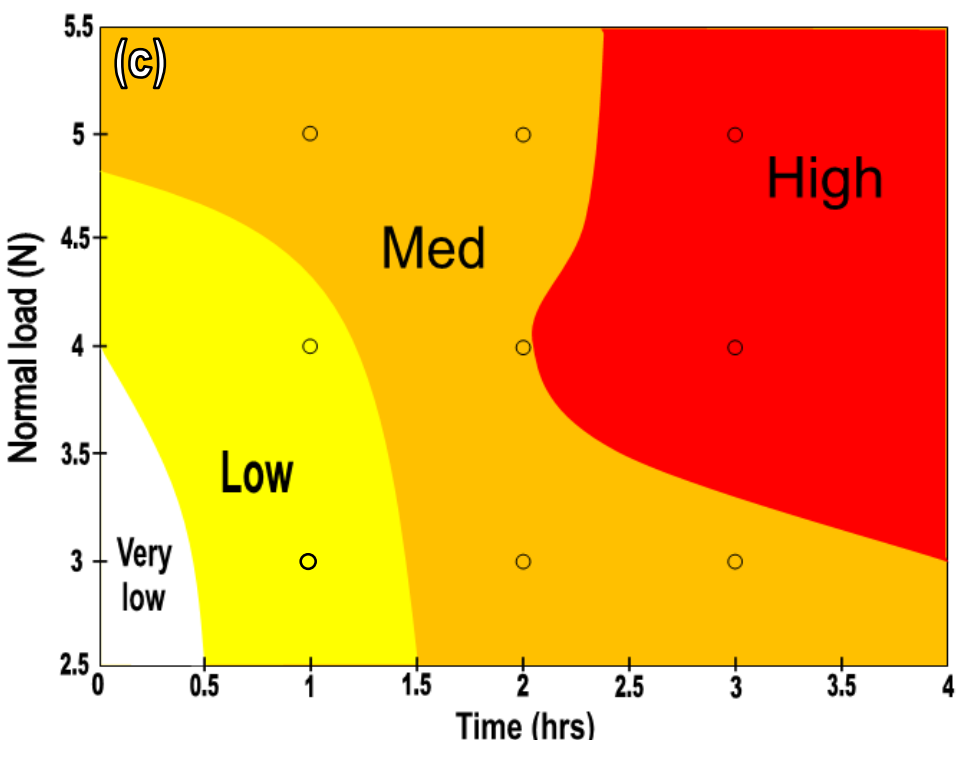

\section{Discussion}

Figure 6(c) - Wear map of Y-TZP in coffee+sugar slurry (load/time)

The longevity of dental implants is associated with many factors, including the mobility at the start of the prosthetic phase, continuing radiolucency around the implant, and peri-implantitis with suppuration. Addressing these issues, may significantly extend this life span. Also, the early failure of the implants can be prevented by properly taking into account the width of the keratinised gingiva and the use of polyglactin sutures [27]. The destructive wear process of the dental tissue (implant) may be linked with physiological, pathological, prophylactic, or due to the finishing method [23]; however, in this study, the focus is only on the tribological behaviour of Y-TZP in two common caffeine containing solutions in a simulated oral cavity environment, assuming successful implantation.

The consumption of both coffee and tea has been recommended, as it has the potential of preventing some serious chronic diseases such as cancer and cardiovascular disorders [28]; however, these caffeine containing solutions may have detrimental effects on dental tissues (dental implants). The caffeine content of coffee and tea beverages depends on the raw material of each product, the manufacturing process, and the preparation method. The caffeine content per $100 \mathrm{ml}$ serving of coffee may vary between 21 and $127 \mathrm{mg}$, whereas this range for tea is between 8.5 and $25.5 \mathrm{mg}$. The phenolic and polyphenolic constituents of these solutions create an acidic environment in the oral cavity. The reported level of tea phenolics, flavan-3-ols (generally known as catechins), in black tea is between 5 and $21 \mathrm{mg} / \mathrm{g}$. The coffee phenolics which mainly consist of chlorogenic acids for medium roast coffees are ranged from 28 to $45 \mathrm{mg} / \mathrm{g}[17,29]$. These numbers indicate why the $\mathrm{pH}$ value is lower in coffee solutions. Commonly, tea and coffee beverages are consumed along with secondary ingredients, for instance creamers (e.g. milk) and sweeteners (e.g. sugar). It should be noted that the addition of the secondary ingredients alters phenolic profiles of tea and coffee [17]; therefore these mixtures should be investigated individually. The results in section 3.1 indicate that, generally, by increasing applied load and sliding distance, higher volume loss is expected. However, bearing in mind that the experiments are conducted in similar conditions, variation of the results for different slurries shows that the properties of the abrasive slurries are as effective as increased load and sliding distance. Excluding the natural structural differences of tea and coffee, the main differences to consider may be the $\mathrm{pH}$ value and the viscosity of these products, which significantly affect the wear rate.

Research shows that, in environments with very high or very low $\mathrm{pH}$ values, wear rate increases. In other words, in very acidic and very alkaline environments, tribo-layers cannot be formed; this leads to constant wear loss during exposure time $[30,31]$.

Figure 7 plots the relationship between volume loss and viscosity; the curve indicates that generally, an increase in viscosity increases volume loss. The $\mathrm{pH}$ values on the curve show a similar trend. It is surprising, however, that with such a minor reduction in $\mathrm{pH}$, such a large difference in wear rate is observed in both solutions and this further suggests that viscosity may play a significant role in the overall trends observed. Also the anomaly in the curve, created by coffee+milk $(\mathrm{pH}=5.6)$, causes a higher volume loss despite having a higher $\mathrm{pH}$ than the previous point. 
This implies that viscosity influences volume loss more than $\mathrm{pH}$. The same anomaly is observed in both tea and tea+sugar slurries, which have an equal $\mathrm{pH}$ value of 5.3 , with the tea+sugar slurry having a higher viscosity. Therefore, high viscosity could be more destructive than high acidity and this also may be linked with particle entrainment issues, with more abrasive particles being captured in the contact in the more viscous environments.

Figure 7 - Volume loss vs. viscosity and $\mathrm{pH}$

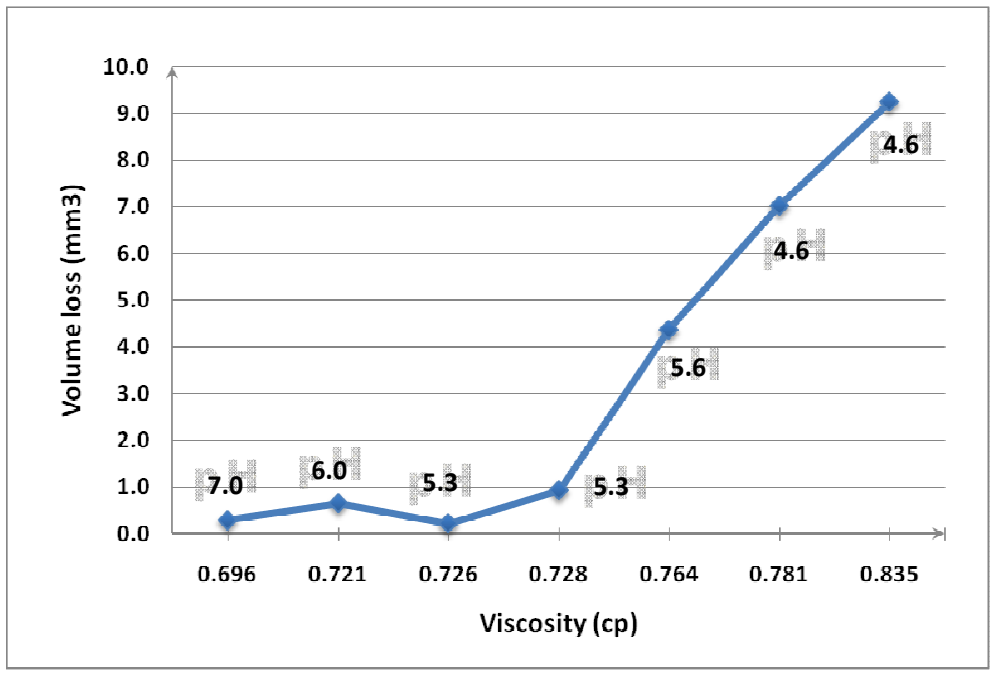

According to the Archard Equation, and many similar studies, there is a linear relationship between wear rate, sliding distance, and the applied load [32, 33]; however, this is not always the case. For example, the tea and tea+sugar slurry wear rates (figure 8) show that higher loads and higher sliding distances do not always cause higher volume loss. This may also be due to entrainment issues associated with abrasive particles at higher loads. Higher loads produce higher pressure in the contact area, which may reduce the frequency of particle entrainment. Also, particles may take longer to entrain in specimens with higher hardness. Moreover, using a softer cratering ball does not always facilitate particle entrainment on the ball's surface $[25,34]$. This indicates that the Archard Equation does not take into account all of the factors that influence wear rates. Because this study investigates the performance of Y-TZP immediately after dental implantation, cratering balls without previously pitted and/or roughened surfaces (the two primary methods of promoting particle entrainment) are used. Particle entrainment occurs gradually during the experiment.
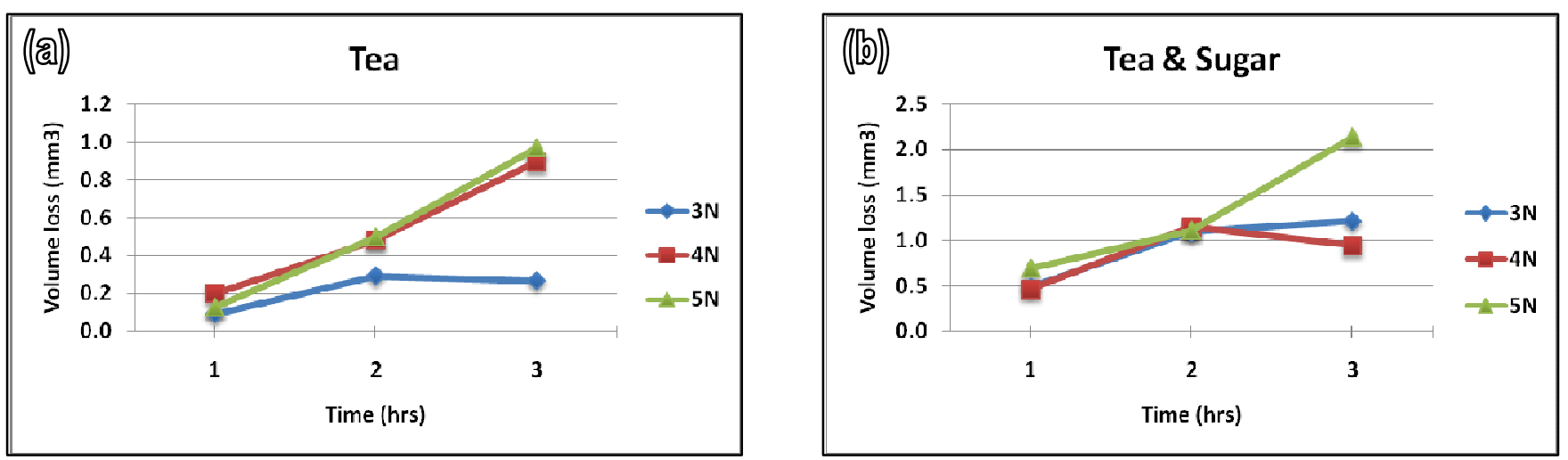

Figure 8 - Volume loss in (a) tea slurry and (b) tea+sugar slurry

Initially, particle entrainment at the counter-face area occurs slowly, but as more particles become entrained further entrainment happens more quickly, resulting in higher wear rates. Examination of the microscopy images suggests that once the treated surface of the sample is fully perforated, the material wears more rapidly and the relationship between wear rate, load, and sliding distance becomes linear. SEM analysis shows evidence that ageing, including micro-cracks and grain pull-outs, occurred before full perforation was reached. After full perforation, the wear scars become deeper, smoother, more uniform, and more circular, without any evidence of ageing. Therefore, the likelihood of ageing is highest before perforation is reached. Because perforation requires more time when using a tea slurry, the probability of ageing with tea is greater than with coffee. 
Based on the information in section 2.4, the combined results from all tea and coffee slurries have been super-imposed into one wear map, figure 9. This provides an overview of the performance of Y-TZP when a 'very low' wear rate is maintained, in the caffeine containing environments (included in this study) during mastication over time. This suggests that the tea environment is less detrimental to Y-TZP implants than that of coffee. It also suggests that Y-TZP implants will last up to twice as long when drinking coffee with milk compared to plain coffee, and up to four times as long compared to coffee with sugar.

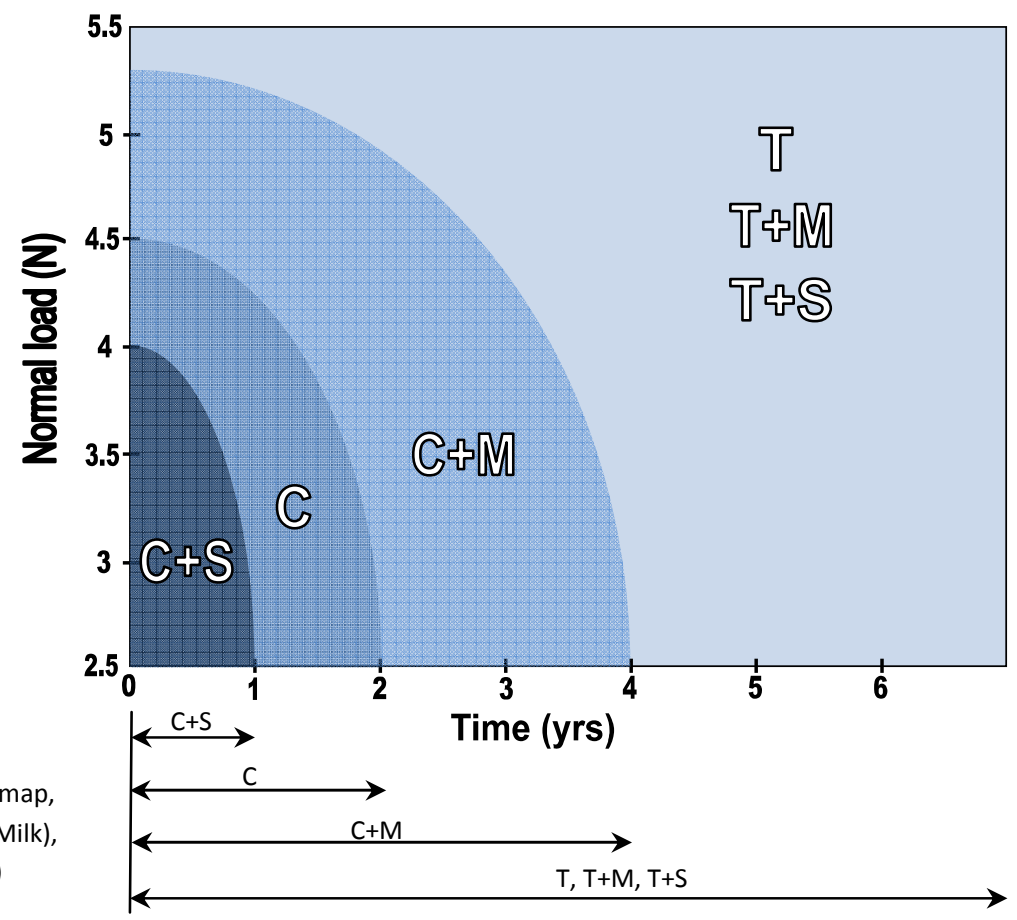

Since the majority of people consume at least one of the tested caffeine containing drinks (tea or coffee) or a carbonated drink daily [35]; therefore, the severity of the mechanical conditions in the conducted tests was necessary to simulate years of mastication in mere hours. Also, it should be noted that the pre-dominant wear regime in this study was 2-body grooving. It has been reported that the wear loss of teeth due to 3-body regimes, which is very likely to happen in the oral cavity, are significantly less than 2-body wear regimes. Furthermore, the influences of the increased load are more significant under 2-body mechanisms [36]. However, the increasing common consumption of fizzy soft drinks creates an environment in the oral cavity that exceeds the acidity (with a pH of 3.0 or lower) and viscosity of the tested drink solutions [37], which has been addressed in previous work by the current authors [38, 39]. The results of these experiments suggest that there are additional factors, which are not included in the Archard Equation, that must be considered in evaluating the performance of Y-TZP dental implants. Evidence shows that viscosity and acidity exacerbate the effects of load and exposure time. Because dental implants are exposed to aqueous environments, the probability of ageing is very high. Therefore, Y-TZP manufacturing processes must be carried out with greater precision, particularly in the addition of stabilisers and the sintering process temperature. Also, surface treatments with greater depth will reduce wear rates. Precise manufacturing will yield Y-TZP that is more resistant to ageing and this may be the key to production of such materials which are resistant to such environments.

Clearly the tribo-chemical environments involved in caffeine containing drinks as described above may have major effects of the longevity of ceramic restorative materials. The difference in the performance of the tribo-layer in both tea and coffee environments is a key to the reduced wear observed in the tea solutions, with the aging process enhanced in the latter solutions. Further work will be to investigate at the nanolayer, the reasons for such differences, thereby providing important new information on materials selection of dental restorative materials.

\section{Conclusions}

(i) A study has been conducted of the micro-abrasion of Y-TZP in tea and coffee environments in which sugar and milk are added to the slurry mixtures.

(ii) The results indicated a greater dependence of wear rate on viscosity than $\mathrm{pH}$.

(iii) The wear rate did not increase directly with an increase in applied load, in the range studied, and this was attributed to entrainment issues associated with abrasive particles at higher loads.

(iv) The reduced wear in tea is associated with a longer aging time, following exposure, to full perforation of the surface. 
(v) Micro-abrasion maps were constructed showing distinct difference in the performance for the ceramic material in the various environments, with the higher wear rates associated with coffee in sugar, linked with significant surface fragmentation and particle detachment in such environments.

\section{Acknowledgements}

The authors wish to extend grateful thanks to Professor Wang-Long Li from Cheng Kung University, Taiwan, and Professor Moo-Chin Wang from Kaohsiung Medical University, Taiwan, who provided the Y-TZP samples for this study.

\section{References}

[1] H. J. Smit, M. L. Grady, Y. E. Finnegan, S.-A. C. Hughes, J. R. Cotton, and P. J. Rogers, "Role of familiarity on effects of caffeine- and glucosecontaining soft drinks.," Physiology \& behavior, vol. 87, no. 2, pp. 287-97, Feb. 2006.

[2] J. F. Tahmassebi, M. S. Duggal, G. Malik-Kotru, and M. E. J. Curzon, "Soft drinks and dental health: a review of the current literature.," Journal of dentistry, vol. 34, no. 1, pp. 2-11, Jan. 2006.

[3] W. Höland et al., "Future perspectives of biomaterials for dental restoration," Journal of the European Ceramic Society, vol. 29, no. 7, pp. 12911297, Apr. 2009.

[4] L. Wang, Y. Liu, W. Si, H. Feng, Y. Tao, and Z. Ma, "Friction and wear behaviors of dental ceramics against natural tooth enamel," Journal of the European Ceramic Society, vol. 32, no. 11, pp. 2599-2606, Aug. 2012.

[5] V. Preis, M. Behr, C. Kolbeck, S. Hahnel, G. Handel, and M. Rosentritt, “Wear performance of substructure ceramics and veneering porcelains.," Dental materials]: official publication of the Academy of Dental Materials, vol. 27, no. 8, pp. 796-804, Aug. 2011.

[6] S. Lawson, "Environmental degradation of zirconia ceramics," Journal of the European Ceramic Society, vol. 15, no. 6, pp. 485-502, Jan. 1995.

[7] J. Chevalier, S. Deville, E. Münch, R. Jullian, and F. Lair, "Critical effect of cubic phase on aging in 3mol\% yttria-stabilized zirconia ceramics for hip replacement prosthesis.," Biomaterials, vol. 25, no. 24, pp. 5539-45, Nov. 2004.

[8] J. Chevalier, "What future for zirconia as a biomaterial?," Biomaterials, vol. 27, no. 4, pp. 535-43, Feb. 2006.

[9] I. Denry and J. R. Kelly, "State of the art of zirconia for dental applications.," Dental materials]: official publication of the Academy of Dental Materials, vol. 24, no. 3, pp. 299-307, Mar. 2008.

[10] C. Lorenzo-Martin et al., "Mechanical behaviour of yttria tetragonal zirconia polycrystalline nanoceramics: dependence on the glassy phase content," Journal of the European ..., vol. 22, pp. 2603-2607, 2002.

[11] A. Medevielle, F. Thevenot, and D. Treheux, "Wear resistance of zirconias. Dielectrical approach," Wear, vol. 213, no. X, pp. 13-20, 1997.

[12] S. Sharifi, M. M. Stack, L. Stephen, W.-L. Li, and M.-C. Wang, “Micro-abrasion of Y-TZP in tea,” Wear, vol. 297, no. 1-2, pp. 713-721, Oct. 2013.

[13] V. Sobolik, R. Zitny, V. Tovcigrecko, M. Delgado, and K. Allaf, "Viscosity and electrical conductivity of concentrated solutions of soluble coffee," Journal of Food Engineering, vol. 51, pp. 93-98, 2002.

[14] A. U. Guler, F. Yilmaz, T. Kulunk, E. Guler, and S. Kurt, "Effects of different drinks on stainability of resin composite provisional restorative materials.," The Journal of prosthetic dentistry, vol. 94, no. 2, pp. 118-24, Aug. 2005.

[15] P. Lambrechts, E. Debels, K. Van Landuyt, M. Peumans, and B. Van Meerbeek, "How to simulate wear? Overview of existing methods.," Dental materials, vol. 22, no. 8, pp. 693-701, Aug. 2006.

[16] G. J. . Fleming, H. S. Jandu, L. Nolan, and F. . Shaini, "The influence of alumina abrasion and cement lute on the strength of a porcelain laminate veneering material," Journal of Dentistry, vol. 32, no. 1, pp. 67-74, Jan. 2004.

[17] M. G. Ferruzzi, "The influence of beverage composition on delivery of phenolic compounds from coffee and tea.," Physiology \& behavior, vol. 100, no. 1, pp. 33-41, Apr. 2010. 
[18] K. Marcus and C. Allen, "The sliding wear of ultrahigh molecular weight polyethylene in an aqueous environment," Wear, vol. 178, no. 1-2, pp. 17-28, Nov. 1994.

[19] S. Wannasri, S. V. Panin, L. R. Ivanova, L. a. Kornienko, and S. Piriyayon, "Increasing wear resistance of UHMWPE by mechanical activation and chemical modification combined with addition of nanofibers," Procedia Engineering, vol. 1, no. 1, pp. 67-70, Jul. 2009.

[20] D.-W. Kim and K.-W. Kim, "Effects of Sliding Velocity and Normal Load on Friction and Wear Characteristics of Multi-Layered Diamond-Like Carbon (DLC) Coating Prepared by Reactive Sputtering," Wear, no. Dlc, Oct. 2012.

[21] B. K. Prasad, S. Das, a. K. Jha, O. P. Modi, R. Dasgupta, and a. H. Yegneswaran, "Factors controlling the abrasive wear response of a zinc-based alloy silicon carbide particle composite," Composites Part A: Applied Science and Manufacturing, vol. 28, no. 4, pp. 301-308, Jan. 1997.

[22] R. S. D.-J. and R. Lewis, "Wear of human teeth: A tribological perspective," Journal of Engineering Tribology, vol. 219, no. 1, pp. 1-18, 2005.

[23] P. Vale Antunes and a. Ramalho, "Study of abrasive resistance of composites for dental restoration by ball-cratering," Wear, vol. 255, no. 7-12, pp. 990-998, Aug. 2003.

[24] L. He, "Mechanical behaviour of human enamel and the relationship to its structural and compositional characteristics.," University of Sydney, 2008.

[25] R. I. Trezona and I. M. Hutchings, “Three-body abrasive wear testing of soft materials," Wear, vol. 233-235, pp. 209-221, 1999.

[26] M. . Stack and M. Mathew, “Micro-abrasion transitions of metallic materials," Wear, vol. 255, no. 1-6, pp. 14-22, Aug. 2003.

[27] Z. H. Baqain, W. Y. Moqbel, and F. a Sawair, "Early dental implant failure: risk factors.," The British journal of oral \& maxillofacial surgery, vol. 50, no. 3, pp. 239-43, Apr. 2012.

[28] G. F. Ferrazzano, I. Amato, A. Ingenito, A. De Natale, and A. Pollio, "Anti-cariogenic effects of polyphenols from plant stimulant beverages (cocoa, coffee, tea).," Fitoterapia, vol. 80, no. 5, pp. 255-62, Jul. 2009.

[29] a. B. Sharangi, "Medicinal and therapeutic potentialities of tea (Camellia sinensis L.) - A review," Food Research International, vol. 42, no. 5-6, pp. 529-535, Jun. 2009.

[30] M. Kalin, S. Novak, and J. Vižintin, "Wear and friction behavior of alumina ceramics in aqueous solutions with different pH," Wear, vol. 254, no. 11, pp. 1141-1146, Oct. 2003.

[31] M. Shabanian and L. C. Richards, "In vitro wear rates of materials under different loads and varying pH.," The Journal of prosthetic dentistry, vol. 87, no. 6, pp. 650-6, Jun. 2002.

[32] M. G. Gee et al., "Progress towards standardisation of ball cratering," Wear, vol. 255, no. 1-6, pp. 1-13, Aug. 2003.

[33] G. B. Stachowiak, G. W. Stachowiak, and J. M. Brandt, "Ball-cratering abrasion tests with large abrasive particles," Tribology International, vol. 39, no. 1, pp. 1-11, Jan. 2006.

[34] M. M. Stack, W. Huang, G. Wang, and C. Hodge, "Some views on the construction of bio-tribo-corrosion maps for Titanium alloys in Hank's solution: Particle concentration and applied loads effects," Tribology International, vol. 44, no. 12, pp. 1827-1837, Nov. 2011.

[35] J. S. Ren et al., "Tea, coffee, carbonated soft drinks and upper gastrointestinal tract cancer risk in a large United States prospective cohort study.," European journal of cancer (Oxford, England]]: 1990), vol. 46, no. 10, pp. 1873-81, Jul. 2010.

[36] J. Zheng and Z. R. Zhou, "Friction and wear behavior of human teeth under various wear conditions," Tribology International, vol. 40, no. 2, pp. 278-284, Feb. 2007

[37] H.-C. Wang, M. M. Stack, W.-L. Li, T.-F. Hong, and M.-C. Wang, "On the construction of wear maps for Y-TZP dental ceramics in aqueous environments: pH, exposure time and impact angle effects," Tribology International, vol. 43, no. 12, pp. 2258-2267, Dec. 2010.

[38] M. M. Stack, H. Jawan, and M. T. Mathew, "On the construction of micro-abrasion maps for a steel/polymer couple in corrosive environments," Tribology International, vol. 38, no. 9, pp. 848-856, Sep. 2005.

[39] C. Hodge and M. M. Stack, “Tribo-corrosion mechanisms of stainless steel in soft drinks," Wear, vol. 270, no. 1-2, pp. 104-114, Dec. 2010. 